\title{
Monitoring Kebocoran Pada Pipa Menggunakan SMS Gateway
}

\section{In the Pipes Leakage Monitoring Using SMS Gateway}

\author{
Hidra Amnur, Defni \& Fatma Adilla \\ Jurusan Teknologi Informasi Politeknik Negeri Padang Kampus Limau Manis Padang \\ Telp. 0751-72590 Fax. 0751-72576
}

\begin{abstract}
Monitoring is the most important thing in a system. Particularly large systems such as the installation of water pipes. Water pipes are installed in various places will be very troublesome to monitor the leak. With the SMS Gateway System, the real data of the sensor water pipes will be displayed and can be accessed on a website. SMS Gateway is an SMS -based system that can be developed in various fields by utilizing the PHP programming language. Through the development of information technology, creates a system that is interconnected to obtain information in real and fast
\end{abstract}

Keywords : Water pipes, Sensor, Monitoring, SMS Gateway, Web, PHP, Gammu, Xampp

\section{PENDAHULUAN}

Air merupakan sumber kehidapan makhluk hidup, tanpa air makhluk hidup tidak akan bisa bertahan lama hidupnya. Untuk memenuhi kebutuhan hidupnya manusia mengalirkan air dari suatu tempat ke tempat tinggalnya. Air tersebut dialiri menggunakan pipa yang tersambung satu sama lain mulai dari sumber air sampai ketujuannya.

Pipa-pipa yang terhubung tersebut kadangkalanya berada di dalam tanah dan tersebar dari lokasi yang relatif luas. Karena pipa-pipa tersebut tertanam didalam tanah, sulit untuk memantau / memonitoring aliran air dalam pipa. Bila terjadi permasalahan pada pipa, seorang harus turun langsung untuk memeriksa kebocoran pipa. Untuk mencari sumber kebocoran dari pipa yang tersambung tersebut tidaklah mudah. Hal ini akan menguras tenaga dan waktu. Untuk mengatasi hal itu digunakan sebuah sensor yang berguna untuk mengukur tekanan air dan kecepatan air dalam pipa pada pipa distribusi.

Dengan adanya sensor, seseorang bisa memonitoring tekanan air dan kecepatan air. Melalui data sensor tersebut dikirimlah sms dan ditampilkan ke web untuk memudahkan dalam memonitoring tekanan dan kecepatan air secara lebih efisien, kapanpun dan dimanapun.

Tujuan dari penelitian sebagai berikut :

1. Bagaimana mengirim informasi dari sensor monitoring tekanan dan kecepatan air pada pipa ke server ?

2. Bagaimana cara membangun sistem sms gateway?

3. Bagaimana cara menyimpan data sms ke database MYSQL?

4. Bagaimana cara menampilkan data yang diterima dengan informatif dalam sebuah aplikasi web?

\section{SMS Gateway}

SMS gateway merupakan sebuah sistem aplikasi yang digunakan untuk mengirim dan atau menerima SMS, dan biasanya digunakan pada aplikasi bisnis, baik untuk kepentingan broadcast promosi, service informasi terhadap pengguna, penyebaran informasi dan lain sebagainya. (Saputra, 2012).

Karena SMS Gateway merupakan sebuah aplikasi, maka fitur yang ada dalam SMS gateway bisa dimodifikasi sesuai dengan kebutuhan. Berikut beberapa fitur yang umum dikembangkan dalam aplikasi SMS Gateway :

a) Auto Reply 
b) Pengiriman massal / broadcast message

c) Pengiriman terjadwal

Untuk membuat sebuah SMS gateway harus mengetahui bahwa yang memegang peranan penting dalam pengiriman SMS adalah SMSC (Short Message Service Center). Yang merupakan jaringan telepon selular yang menangani pengiriman SMS.

\section{Gammu}

Gammu adalah sebuah aplikasi crossplatform yang digunakan untuk menjembatani / mengkomunikasikan antara database SMS gateway dengan SMS devices. Aplikasi gammu berupa daemon yang berjalan secara background. Setiap saat, gammu memonitor SMS devices dan database SMS gateway.

Saat ada sms masuk ke SMS devices, maka gammu langsung memindahkannya ke dalam inbox dalam database SMS gateway. Sebaliknya saat aplikasi pengirim SMS memasukkan SMS ke dalam outbox dalam database SMS gateway, maka gammu mengirimkannya melalui SMS devices, dan memindahkan SMS ke senditem dalam database.(Gunawan, 2003).

\section{Xampp}

Xampp merupakan salah satu aplikasi untuk membangun aplikasi website dinamis di lokalhost atau yang belum terkoneksi dengan internet. Xampp adalah software web server apache yang di dalamnya tertanam server MySQL yang didukung dengan bahasa pemrograman PHP untuk membuat website yang dinamis. XAMPP sendiri mendukung dua sistem operasi yaitu windows dan Linux. (SMS C G, 2013).

Di dalam XAMPP ada 3 komponen utama yang di tanam di dalamnya yaitu web server Apache, PHP, dan MySQL

\section{Apache}

Apache merupakan web server yang digunakan untuk menampilkan website di internet seperti menggunakan Mozilla firefox, Google Crome, IE, Safari berdasarkan kode-kode yang di tulis di dalam website tersebut baik menggunakan bahasa pemrograman HTML maupun PHP yang mengambil suatu database yang dibangun di MySQL, sehingga terbentuklah sebuah website yang dapat di lihat di Mozilla firefox dan lain-lain. Apache sendiri bersifat opensource sehingga dapat digunakan oleh siapa saja dan dikembangkan oleh siapa saja.(SMS C G, 2013).

\section{PHP}

PHP merupakan bahasa pemrograman yang di digunakan untuk membuat website dinamis yang memungkinkan kita melakukan update website setiap saat. Berbeda dengan HTML yang source kodenya di tampilkan di website, source code PHP tidak di tampikan di halaman muka suatu website karena PHP diolah dan diproses di server, PHP bersifat server-side scripting yang mampu berjalan di brbagai system operasi seperti windows, Linux, Mac OS, dll.(Gammu. 2014)

PHP memiliki kedinamisa dalam hal database yang bisa dihubungkan dengan PHP seperti MySQL, Oracle, MS Access, PostgreSQL. Namun untuk pemrograman website yang paling digunakan adalah MySQL.

\section{MySQL}

MySQL dapat digunakan untuk membuat dan mengola database beserta isinya. Pengguna dapat memanfaatkan MySQL untuk menambahkan, mengubah dan menghapus data yang berada dalam database. MySQL merupakan sisitem manajemen database yang bersifat relational. Artinya data-data yang dikelola dalam database akan diletakkan pada beberapa tabel yang terpisah sehingga manipulasi data akan menjadi jauh lebih cepat.(Gammu. 2014)

\section{Website}

Website merupakan kumpulan halaman yang menampilkan informasi data teks, data gambar diam atau gerak, data animasi, suara, video dan atau gabungan dari semuanya, baik 
yang bersifat statis maupun dinamis yang membentuk satu rangkaian bangunan yang saling terkait dimana masing-masing dihubungkan dengan jaringan-jaringan halaman (hyperlink).(Wiratama. 2013).

\section{Sensor}

Sensor adalah sebuah alat yang berfungsi untuk mengolah variasi gerak, panas, cahaya atau sinar, magnetis, dan kimia menjadi tegangan serta arus listrik. Sensor juga berfungsi sebagai alat untuk mendeteksi dan untuk mengetahui magnitude. Sensor sendiri sering digunakan dalam proses pendeteksi untuk proses pengukuran. Sensor yang sering menjadi digunakan dalam berbagai rangkaian elektronik antara lain sensor cahaya, sensor suhu, sensor tekanan, sensor kecepatan.(Alat Uji. 2014)

\section{Sensor Kecepatan}

Flow meter air adalah jenis liquid yang mana basenya adalah air. Pada dasarnya pada flow meter terdapat dua bagian yang utama yaitu sensor dan indicator. Flow Sensor digunakan untuk menangkap prilaku dari fluid yang akan diukur yang diteruskan ke indicator sehingga tujuan dari pemasangan flow meter sesuai dengan yang tujuan yang diharapkan.(Alat Uji. 2014).

\section{Sensor Tekanan}

Sensor tekanan adalah sensor untuk mengukur tekanan suatu zat. Tekanan (p) adalah satuan fisika untuk menyatakan gaya (F) per satuan luas (A). Satuan tekanan sering digunakan untuk mengukur kekuatan dari suatu cairan atau gas.

Satuan tekanan dapat dihubungkan dengan satuan volume (isi) dan suhu. Semakin tinggi tekanan di dalam suatu tempat dengan isi yang sama, maka suhu akan semakin tinggi. Hal ini dapat digunakan untuk menjelaskan mengapa suhu di pegunungan lebih rendah dari pada di dataran rendah, karena di dataran rendah tekanan lebih tinggi.

Prinsip kerja dari sensor tekanan ini adalah mengubah tegangan mekanis menjadi sinyal listrik. kurang ketegangan didasarkan pada prinsip bahwa tahanan pengantar berubah dengan panjang dan luas penampang. Daya yang diberikan pada kawat menyebabkan kawat bengkok sehingga menyebabkan ukuran kawat berubah dan mengubah tahanannya.(Sakur, 2005).

\section{Data Logger}

Data logger (perekam data) adalah sebuah alat elektronik yang mencatat data dari waktu ke waktu yang terintegrasi dengan sensor. Atau secara singkat data logger adalah alat untuk melakukan data logging.(Peranginangin, 2006).

Biasanya ukuran fisiknya kecil, bertenaga baterai, portabel, dan dilengkapi dengan mikroprosesor, memori internal untuk menyimpan data dan modul GSM yang dapat mengirim notifikasi SMS.

Data logger memiliki kemampuan secara otomatis mengumpulkan data setiap 24 jam. Setelah diaktifkan, data logger digunakan dan ditinggalkan untuk mengukur dan merekam informasi selama periode pemantauan. Hal ini dapat memungkinkan untuk mengetahui gambaran tentang kondisi lingkungan yang dipantau.

\section{METODOLOGI}

Arsitektur sistem terdiri dari perangkat yang digunakan, langkah kerja sistem monitoring yang dibuat dan sistematika pengiriman dan penerimaan sms serta bentuk pelaporan hasil monitoring ke dalam website.

Gambar 1 menunjukkan arsitektur sistem yang akan dibuat,

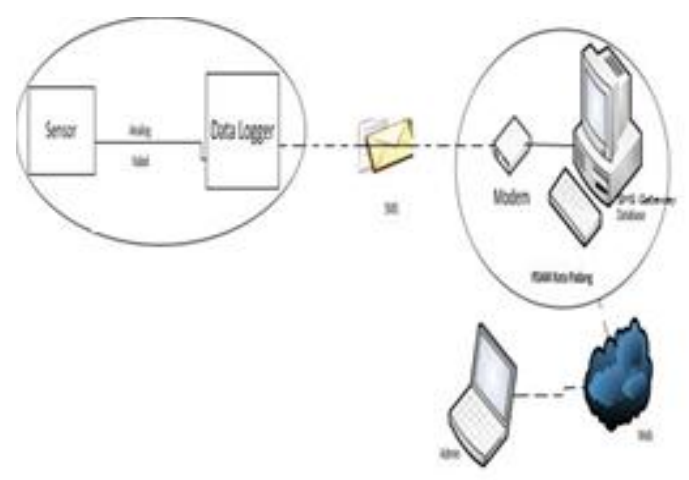

Gambar 1. Arsitektur Sistem

Berikut penjelasan arsitektur sistem di atas: 
1. Sensor akan mengirimkan data analog dalam satuan $\mathrm{mA}$ ke data logger. Data yang diterima data logger diproses menjadi satuan $\mathrm{L} / \mathrm{s}$

2. Data logger akan mengirimkan data melalui SMS ke modem

3. SMS dari Modem akan diteruskan ke komputer,

4. sms tersebut akan dikelola oleh SMS gateway dan data akan disimpan kedalam database

5. data didalam database akan ditampilkan ke website sebagai informasi dari tekanan dan kecepatan air.

Pada gambar 2 menunjukan diagram alir proses SMS. Pada proses ini, data yang didapat dari sensor akan dikirimkan melalui SMS. Data yang diterima akan disimpan di dalam database gammu. Proses selanjutnya yaitu melalui tahapan identifikasi data, jika data yang diterima tidak diawali denga kata 'log' maka gammu akan mengirim sms notifikasi kesalahan dan jika data diawali kata 'log' maka data akan disimpan kedalam database loger dan akan ditampilkan melalui web.

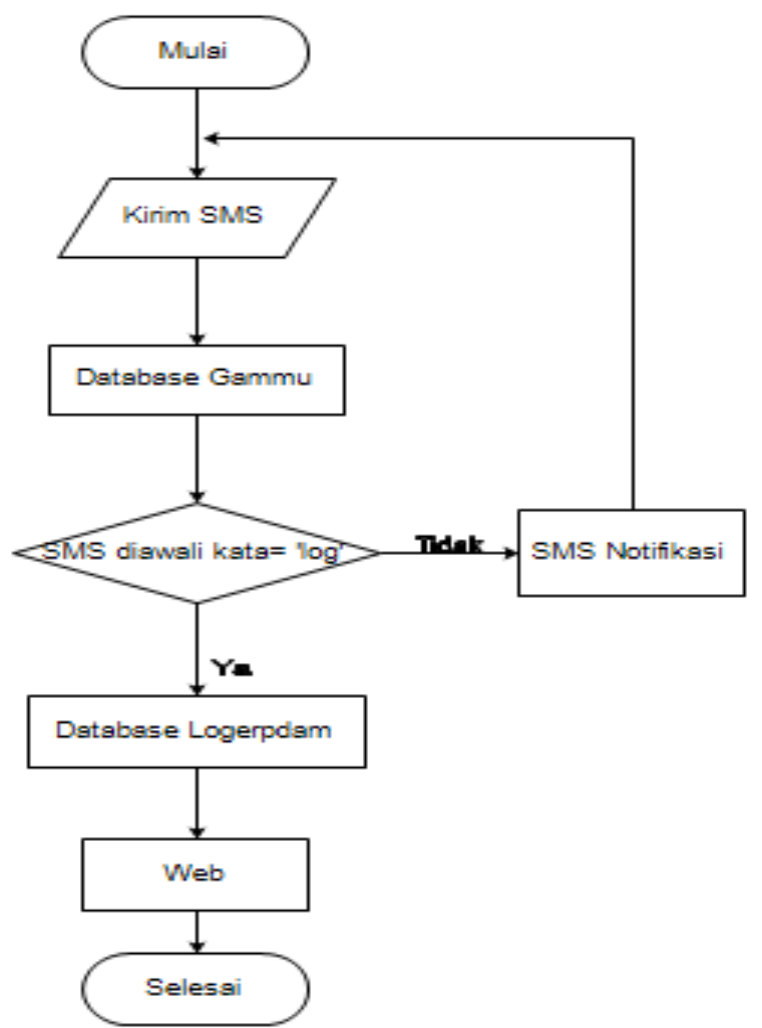

Gambar 2. Diagram Alir Proses SMS

\section{Perancangan Database}

Berikut adalah rancangan database yang dapat diuraikan sesuai dengan kebutuhan yang diperlukan sebagai media penyimpanan data.

Tabel 1. Tabel Log

\begin{tabular}{|l|l|l|}
\hline Nama Field & Tipe Data & Keterangan \\
\hline Waktu & $\begin{array}{l}\text { Timestamp } \\
\text { not null }\end{array}$ & Waktu \\
\hline id_sensor & $\begin{array}{l}\text { Char(10) } \\
\text { not null }\end{array}$ & Kode sensor \\
\hline Tekanan & $\begin{array}{l}\text { Decimal(10, } \\
\text { 0) not null }\end{array}$ & $\begin{array}{l}\text { Nilai } \\
\text { tekanan air }\end{array}$ \\
\hline Kecepatan & $\begin{array}{l}\text { Decimal(10, } \\
\text { 0) not null }\end{array}$ & $\begin{array}{l}\text { Nilai } \\
\text { kecepatan } \\
\text { air }\end{array}$ \\
\hline
\end{tabular}

Tabel log merupakan tabel yang berfungsi untuk menyimpan data tekanan dan kecepatan air

Peralatan yang dibutuhkan antara lain :

1. Sensor, sensor yang digunakan SITRANS F M MAG $5100 \mathrm{~W}$, alat ini merupakan sensor untuk semua aplikasi air seperti air tanah, air minum, air, air limbah,

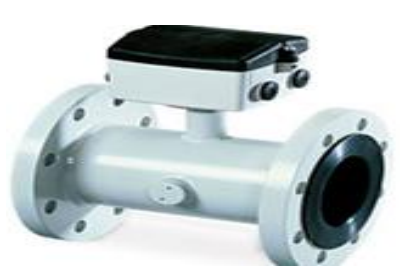

Gambar 3. Sensor Siemens Sitrans F M MAG5000

2. Data Logger, Data logger yang digunakan adalah data logger Sofrel LS42 seperti gambar 4.4.

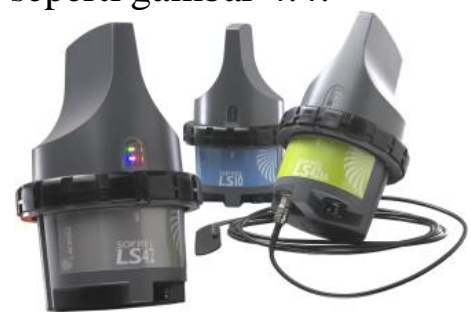

Gambar 4. Sofrel LS 42

3. Modem, Modem yang digunakan adalah modem vodafone mobile broadband k3770 


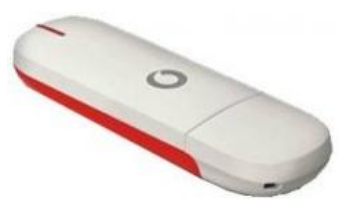

Gambar 5.

Modem Vodafone K3770

4. Server / Komputer PC

Personal Computer (PC) / Server digunakan sebagai monitoring, database server dan web server

Perangkat lunak (software) yang akan digunakan adalah sebagai berikut;

1. Gammu 1.33.0

Digunakan untuk mengontrol pengambilan SMS, backup dan mengirim SMS.

2. Xampp 1.8.3.

Xampp digunakan sebagai web server menggunakan php, dan database server dengan mysql.

\section{Implementasi}

Implementasi dilaksanakan setelah tahap perancangan hardware dan software yang akan digunakan

\section{Pemasangan Peralatan}

Dari peralatan diatas maka sesuai dengan arsitektur system maka dilakukan pemasangan, seperti keterangan berikut ini

1. Pada Pipa Air

Sensor dan data logger dipasang pada pipa sseperti gambar berikut ini :

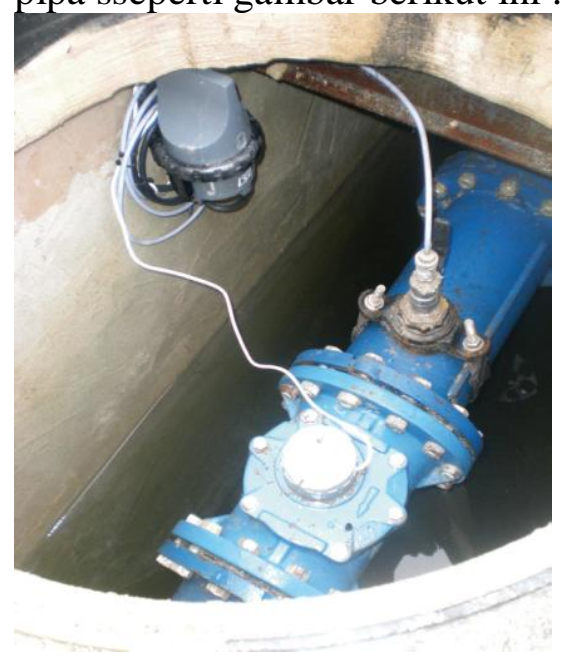

Gambar 6.

Sensor \& Data Logger pada Pipa
Informasi tekanan dan kecepatan air yang diperoleh dari sensor akan dikirim ke data logger. Data logger akan mengirim sms ke Server

2. Pada PC / Server

PC/Server akan dipasangkan modem sebagai penerima sms dari data logger. Informasi yang disms akan disimpan kedalam database

\section{Pemasangan Software}

1. Install Driver Modem

Setelah driver modem terinstall, lihat port modem yang aktif dapat dilihat di device manager. Pada gambar 1. terlihat bahwa port yang dgunakan adalah port (com15).

2. Install dan Konfigurasi Gammu Instal aplikasi gammu kedalam direktori C. Copy file 'gammurc' dan 'smsdrc' pada

'C:〈gammulshareldoc \gammulexamples\ config' ke 'C:Igammulbin'. File gammurc digunakan untuk konfigurasi modem yang di gunakan agar gammu dapat mendeteksi modem. Edit file 'gammurc' bagian "device" disesuaikan dengan port yang aktif pada device manager, sedangkan untuk "connection" sesuaikan dengan modem yang digunakan. pada modem ini tipe connection-nya "at 19200" seperti gambar 7 .

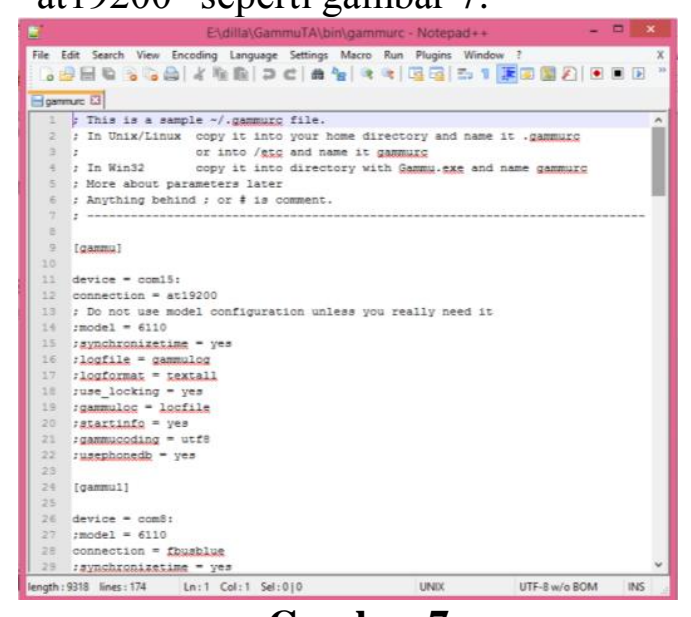

Gambar 7.

Tampilan Script Gammurc

Untuk mengetahui apakah konfigurasi yang di lakukan berhasil atau tidak, 
dapat mengetahuinya melalui command prompt . masuk ke dalam direktori C: Igammulbin\ dan jalankan perintah 'gammu identify' seperti gambar 8 .

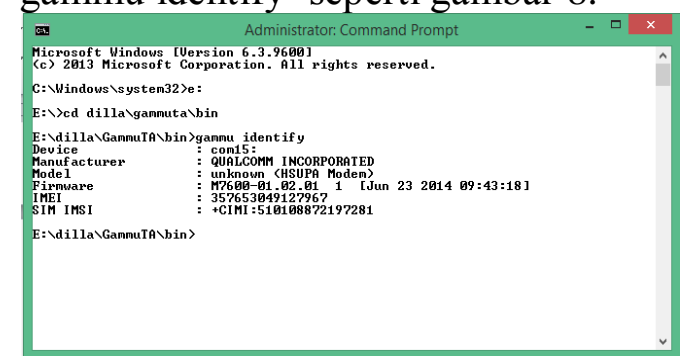

Gambar 8. Tes Koneksi Gammu

3. Install dan Konfigurasi Xampp

Install Xampp dan jalankan service apache dan mysql pada 'xampp control panel'

Import format table untuk database 'gammu' dengan script 'mysql.sql' pada direktori 'C: \gammu\share $\backslash$ doc gammu\examples\sqAmysql.sql' seperti gambar 9.

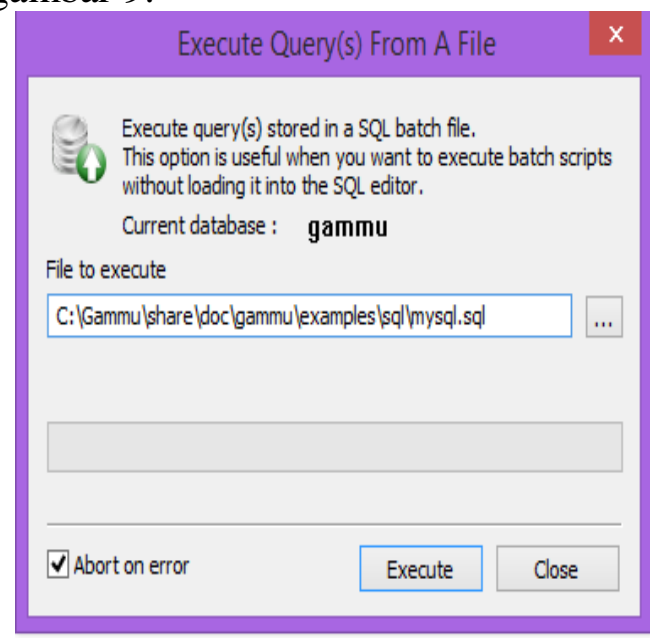

Gambar 9.

Import Database Gammu

Agar aplikasi gammu bisa tersambung dengan database MYSQL, maka lakukan pengeditan pada file 'smsdrc'. Pengeditannya dapat dilakukan dengan menyesuaikan perangkat dan database yang sudah terpasang .

Install service 'GammuSMSD' dengan menggunaka script 'gammu-smsd $-c$ smsdrc $-i$ ' seperti yang terliat pada gambar 10.

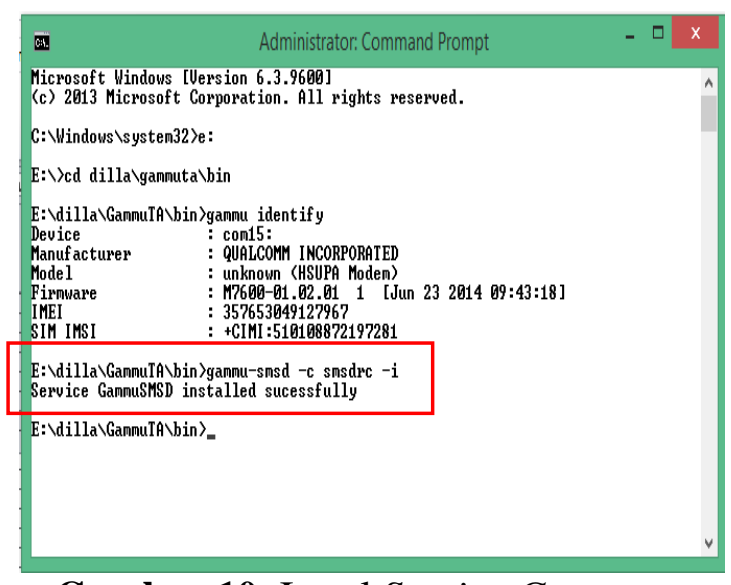

\section{Gambar 10. Instal Servica Gammu}

Buka 'services.msc', dan jalankan 'Gammu SMSD Service' untuk menjalankan gammu seperti yang terlihat pada gambar 11 .

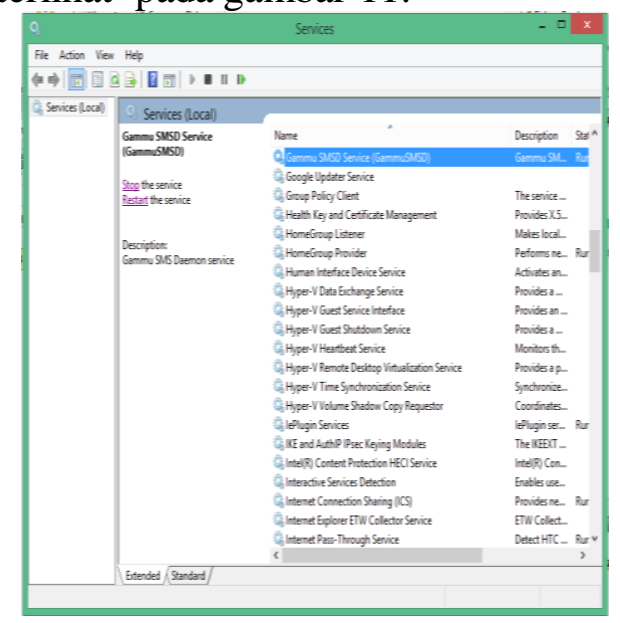

Gambar 11.

Menjalankan Service Gammu

4. Mensetting format sms yang diterima SMS harus di awali dengan kata "log" dan pembatas datanya menggunakan simbol ";" agar SMS dapat di proses. Kata 'log' merupakan kata kunci yang akan diprosos, '01' merupakan id sensor, ' 100 ' merupakan nilai dari sensor tekanan, '300' merupakan nilai sensor kecepatan.

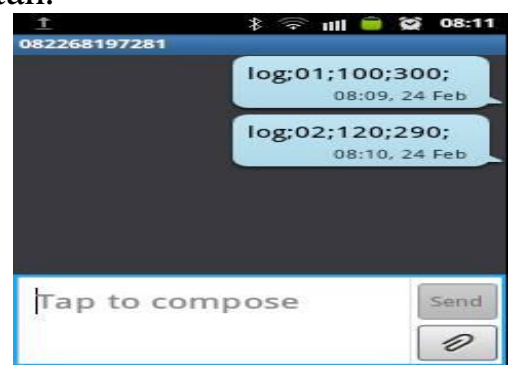

Gambar 12. Contoh Format SMS 
Setelah SMS berhasil terkirim maka data SMS tersebut akan disimpan didalam database gammu $\square$ tabel inbox seperti gambar 13.

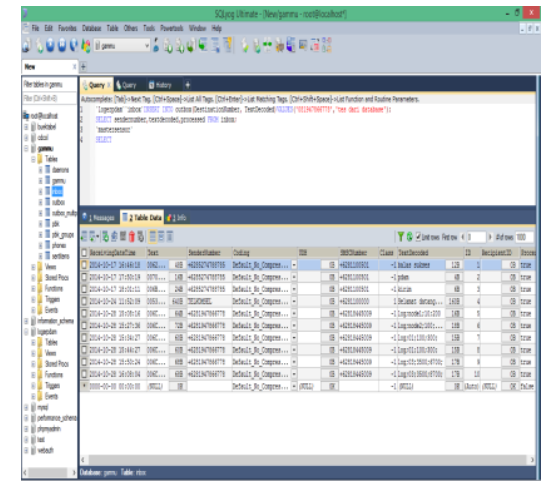

Gambar 13. Tampilan Tabel Inbox Jika format sms salah maka akan dikirim sms pemberitahuan sms salah. Berikut potongan skrip phpnya.

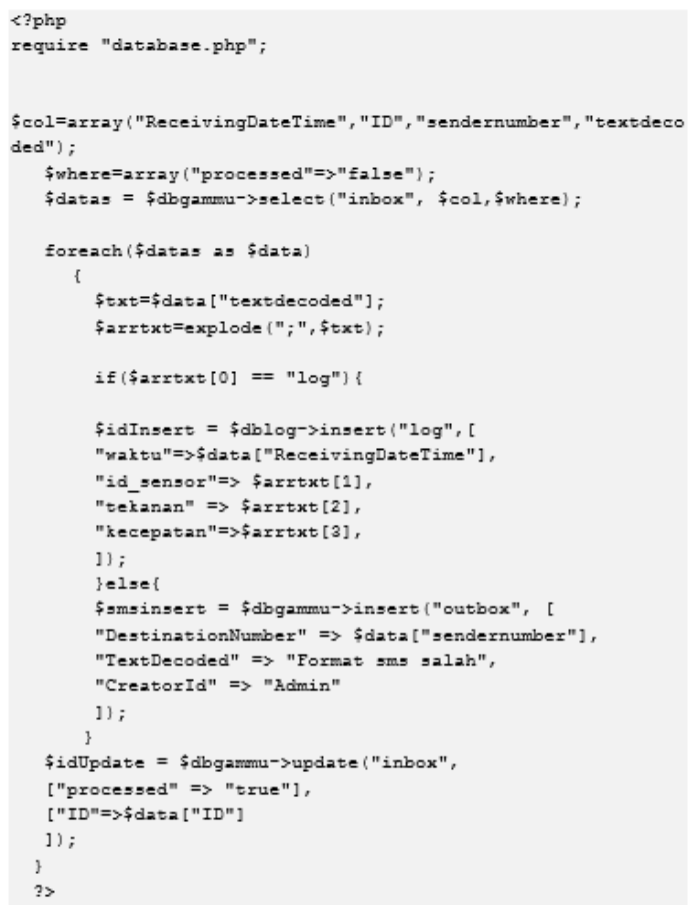

Gambar 14. Skrip PHP untuk SMS

5. Membuat Tampilan Web dari Monitoring

Data dari tabel log akan ditampilkan melalui web. Pada tampilan web akan terlihat informasi mengenai tekanan air dan kecepatan air yang akan di tapilkan dalam bentuk grafik dan tabel. Berikut merupakan tampilan dari web:

Tampilan web berupa grafik

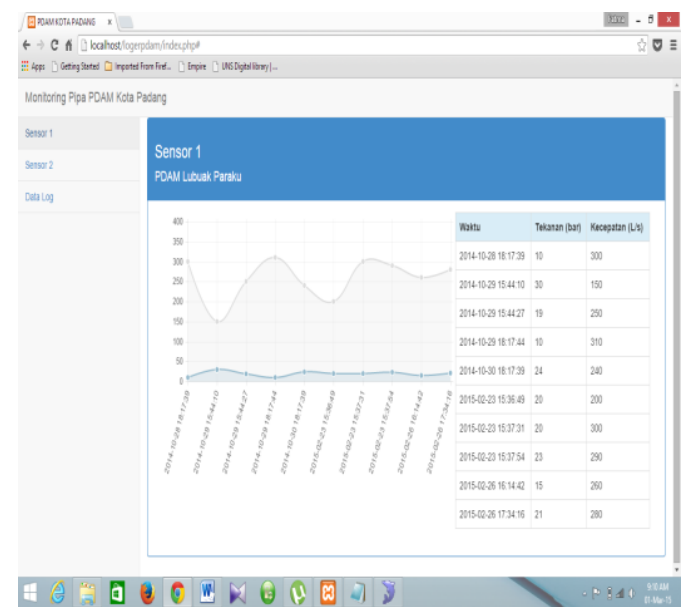

Gambar 15. Tampilan Grafik

Halaman data log merupakan halaman yang menampilkan semua data dalam sehari. Pada halaman ini admin dapat melihat semua data dengan memilih tanggal tertentu dan sensor tertentu seperti gambar 16.

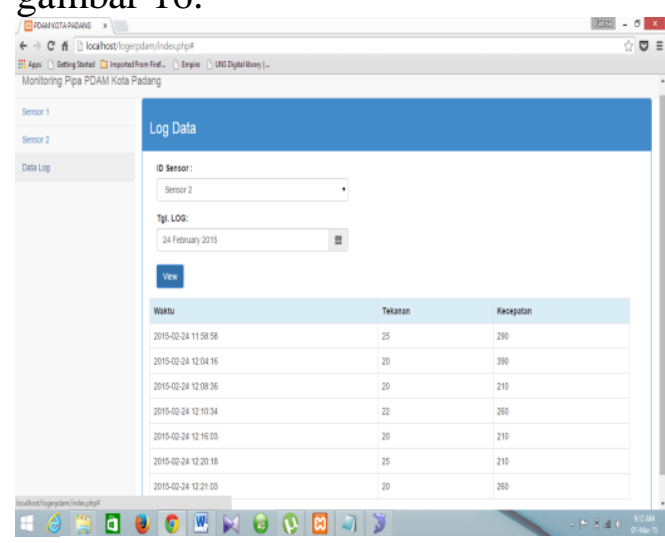

Gambar 16. Halaman Data Log

\section{HASIL DAN PEMBAHASAN}

\section{Pengujian Input SMS sesuai format}

Apabila data yang dikirimkan sesuai dengan format SMS maka data yang disimpan di tabel inbox akan diproses dan dimasukan kedalam tabel log seperti gambar 17, gambar 18 dan gambar 19.

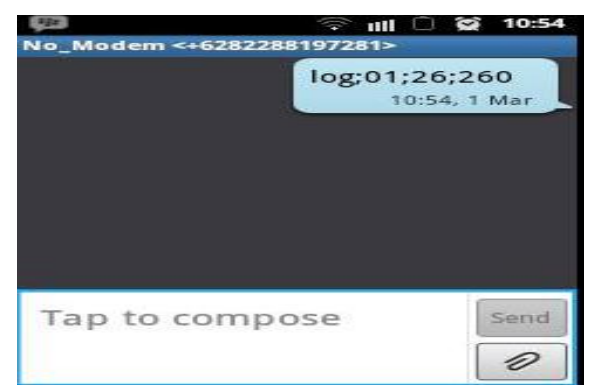

Gambar 17. Format SMS yang Benar 


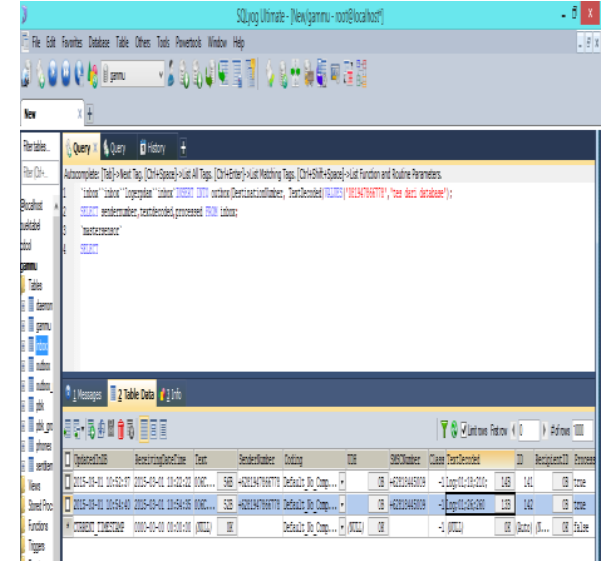

Gambar 18.

SMS Disimpan di Dalam Tabel Inbox

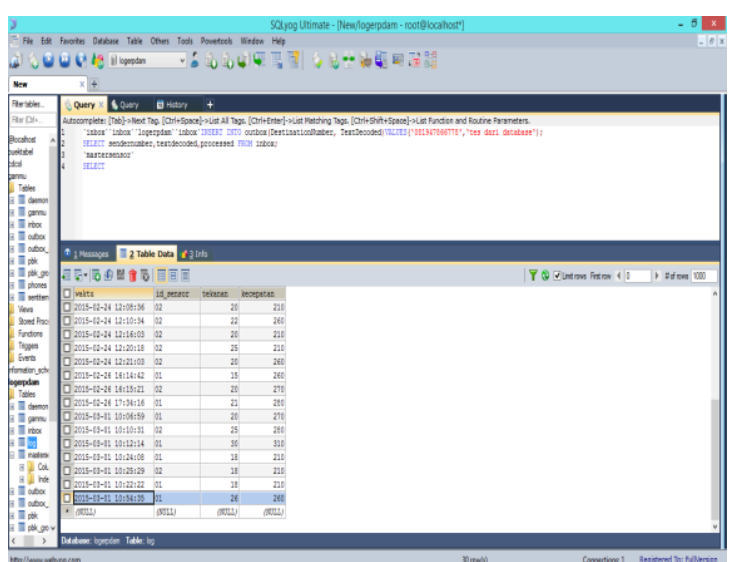

Gambar 19. Data SMS Yang di Proses dan Dimasukan ke Dalam Tabel Log

\section{Pengujian Input SMS tidak sesuai format}

Apabila data yang dikirimkan tidak sesuai dengan format SMS, maka data hanya disimpan di dalam tabel inbox dan tidak diproses. Gammu akan secara otomatis mengirimkan pesan SMS ke nomor pengirim yang isinya "format SMS salah" seperti gambar 20 gambar 21 gambar 22 dan gambar 23.

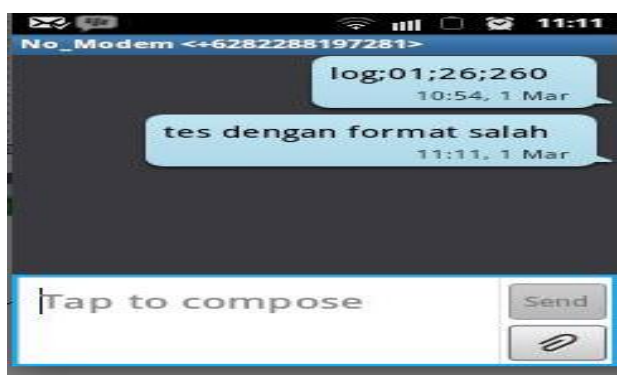

Gambar 20.

Contoh SMS Dengan Format Salah

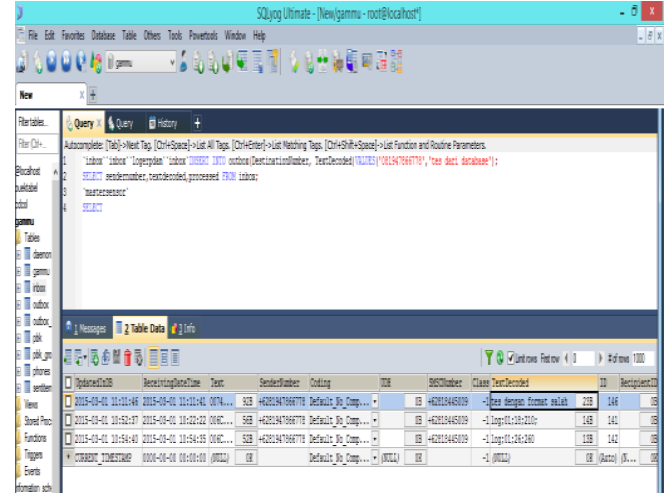

Gambar 21.

SMS Disimpan di Dalam Tabel Inbox

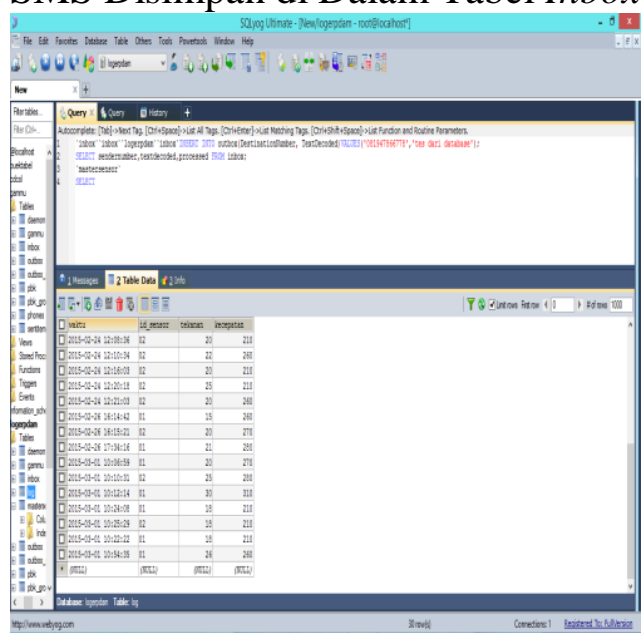

Gambar 22.

Data SMS Tidak Masuk ke Dalam Tabel Log

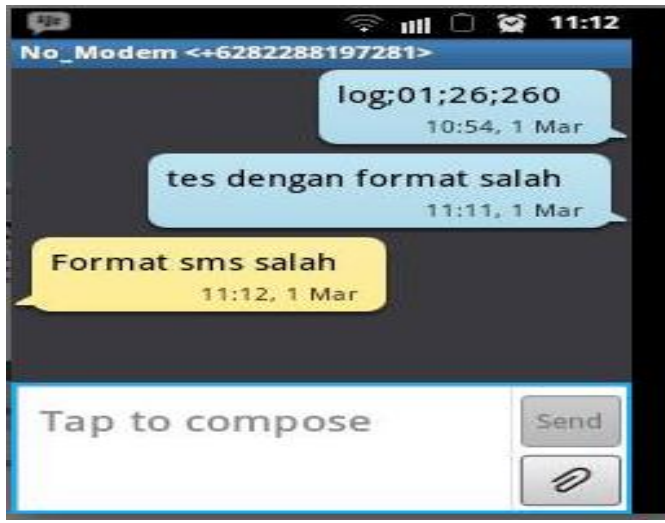

Gambar 23.

SMS Balasan dari Gammu

\section{SIMPULAN}

Dari implementasi dan pengujian sistem sms gateway untuk monitoring kebocoran pipa melalui informasi tekanan air dan kecepatan air pada pipa, dapat ditarik beberapa kesimpulan diantaranya adalah: 
1. Aplikasi web ini digunakan untuk mempermudah dalam memperoleh informasi tekanan air dan kecepatan air dimanapun dan kapanpun, sehingga apabila terjadi kebocoran dapat diketahui dengan segera

2. Apliasi web akan menampilkan informasi data sensor berupa tabel dan grafik.

3. Apabila terdapat kesalahan data dalam pengiriman SMS, gammu akan secara otomatis mengirimkan pesan notifikasi ke nomor pengirim.

4. Kinerja sistem SMS gateway mulai dari penerimaan sms ke modem, proses di dalam database, menampilkan data ke web dan instruksi untuk mengirimkan SMS balasan berjalan dengan baik.

\section{SARAN}

Adapun beberapa saran, diantaranya:

1. Diharapkan untuk selalu mengecek nomor port modem sebelum menjalankan gammu, karena port modem akan selalu berbeda nomornya saat dihubungkan ke PC.

2. Apabila SMS yang dikirimkan tidak masuk ke database, biasanya itu diakibatkan karena service gammu tidak jalan. Sebaiknya pastikan bahwa service gamu telah di jalankan.

3. Pengujian sistem masih menggunakan modem GSM untuk internet. Selanjutnya diharapkan untuk menggunakan modem khusus SMS Gateway, agar pesan masuk dan keluar dapat ditangani dengan baik.

4. Dapat dilakukan pengembangan dengan menambahakan menu print pada aplikasi $w e b$, yang berfungsi untuk menjadikan informasi dalam sebuah dokumen baik dalam format PDF (.pdf) , Ms.Word (.doc) dll.

5. Dapat dicobakan untuk selain pipa air.

\section{DAFTAR PUSTAKA}

Alat Uji. 2014: Sensor Tekanan, URL: http://www.alatuji.com/kategori/302/sen sor-tekanan. Diakses pada tanggal 1 November 2014
Gunawan, Ferry. 2003: Membuat Aplikasi SMS Gateway Server dan Client dengan Java dan PHP. PT Elex Media Komputindo: Jakarta.

Gammu. 2014: Gammu, URL:

http://wammu.eu/gammu/. Diakses pada tanggal 28 Oktober 2014.

Peranginangin, Kasiman. 2006: Aplikasi Web dengan PHP dan MYSQL. Andi: Yogyakarta.

Saputra, Agus dan Feni Agustin. 2012: Membangun Sistem Aplikasi ECommerce dan SMS. PT Elex Media Komputindo: Jakarta.

Sakur, Standy B. 2005: Aplikasi Web Server. Andi: Yogyakarta.

SMS Center Gateway, 2013: SMS Center Gateway, URL: http://www.smscentergateway.com/2013 /10/smsgatewayadalah.html. Diakses pada tanggal 28 Oktober 2014.

Wiratama. 2013: Flow Meter Air, URL: http://www.wiratama.web.id/ item?item _id $=5792708291461120$. Diakses pada tanggal 1 November 2014 